\title{
3-D Wire Cloth Electrode for Higher Throughput DielectrophoreticSeparation of Bacterial Cell
}

\author{
Fadhila Nadzri, Zurina Zainal Abidin, Jamil Mohd Salleh
}

\begin{abstract}
Dielectrophoresis (DEP) is one of an alternative way for cell separation. It has mainly been limited to processing small volumes due to constrain in fabrication of microelectrode over large surface areas. This work incorporated the wire cloth electrode fabricated using textile technology into a high throughput chamber experiment. The plain-weave wire cloth consists of $71 \mu \mathrm{m}$ stainless steel wires as the microelectrode arrays hold together by polyester yarn warp. This work determines the cell separation yield with parameters on applied voltage, flow rate and cell concentration as well as its optimized variables on the chamber width of $1.2 \mathrm{~cm}$ and $2.5 \mathrm{~cm}$. The optimum voltage achieved was 30Vpk-pk, with flow rate of $3.5 \mathrm{ml} / \mathrm{min}$ and maximum cell concentration of $2.08 \times 107 \mathrm{cells} / \mathrm{ml}$. In chamber width comparison, $1.2 \mathrm{~cm}$ width chamber gives better total percentage yield of $96 \%$ than the $2.5 \mathrm{~cm}$ width chamber of $85 \%$ total percentage yield.
\end{abstract}

Keywords:-Dielectrophoresis, Large Scale, wire cloth

\section{INTRODUCTION}

Biochemical and bioprocessing has gained an overwhelming recognition due to constant need for rapid and robust technologies. More and more industries nowadays were moving towards developing process based on biochemical and biotechnology because of their inherent advantages[1]. However, when dealing with bioprocessing, the usual constraint is the downstream processing mainly bioseparation involving the recovery and purification of the desired product from the upstream process whereby the percentage of recovery is low. These kinds of trends and challenges in modern bioseparation have led to various discoveries and novel approaches in the techniques used.

Dielectrophoresis (DEP) is one of an alternative way for cell separation that involved the motion of particles caused by the interaction of cell induced dipole in non-uniform AC electric fields[2]. It has certain advantages over other methods mostly because of its high resolution or selectivity. Additionally, by DEP, cell viability can be maintained and the process can be conducted under sterile condition. Previous works regarding DEP involved separating live and dead cells or monocytes[3,4], manipulating cells using travelling electric fields[5,6], and application in the water[7] and wastewater treatment[8]. In nanotechnology, numerous works have been done regarding viruses[9,10]. Alternatively, research on the use of higher throughput have

Revised Manuscript Received on April 12, 2019.

FadhilaNadzri,Department of Chemical and Environmental Engineering, Faculty of Engineering, Universiti Putra Malaysia, 43400 Serdang, Selangor

ZurinaZainalAbidin,Department of Chemical and Environmental Engineering, Faculty of Engineering, Universiti Putra Malaysia, 43400 Serdang, Selangor. (zurina@upm.edu.my)

JamilMohdSalleh, Department of Applied Science, UniversitiTeknologi Mara, 40450 Shah Alam, Selangor increased with 3-dimensional insulator[7] or electrode separator[3,11,12], wire cloth electrode separator [13], filter chip separator[14] and integrated microfluidic chip [15]. The process has always been limited to small throughput due to restriction in fabrication of microelectrode for large surface areas which mostly applied the lab-on-a-chip device and printed circuit board. Hence, the fabrication of 3-D microelectrode using textile technology is implemented to address the surface area issue. While previous study[13] proved to be effective for fungi species such as yeast (Saccharomyces cerevisiae), this study targeted smaller microorganism using bacteria Escherichia coli with smaller electrode diameter.

\section{MATERIALS AND METHODS}

The methodology involves the construction of the chamber, the cell preparation, the DEP experiment and the analytical methods involved.

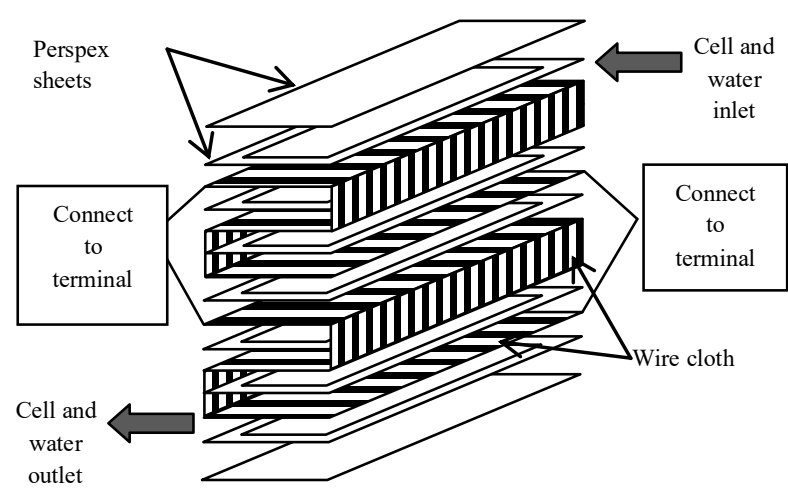

Figure 1 Diagram of large scale DEP separation chamber

\subsection{Wire Cloth Fabrication and Electric Field Simulation}

$71 \mu \mathrm{m}$ stainless steel wire were weaved into plain waeve pattern using textile machine with weft setting of 93 part per inch (PPI) and $16 \mu \mathrm{m}$ polyester yarn size (83 decitex) to produce $204 \mu \mathrm{m}$ gap. A study of the electric field strength and pattern generated by electrodes of the wire cloth was performed using FEMLAB 3.0 (COMSOL $^{\mathrm{TM}}$ ) using the Electromagnetic module [13,16]. The drawn system mimicked the actual wire cloth electrode and electric field was simulated.

Published By: 


\subsection{Cell preparation.}

Escherichia coli (Biotechnology Lab, UPM) was cultured overnight in nutrient broth (Oxoid, UK) at $37^{\circ} \mathrm{C}$ in a 150 rpm incubator shaker (Stuart, Fisher Scientific, UK). The cell was then harvested, centrifuged at $5000 \mathrm{rpm}$ (Heraeus, Thermo Scientific, USA) and washed four times with distilled water. Early concentration of cells (optical density, OD) suspended in distilled water was measured through $600 \mathrm{~nm}$ wavelength of a UV spectrophotometer (Thermo Electron Corporation, UK).

\subsection{Construction of chamber.}

The DEP chamber for higher throughput (Figure 1) consisted of 7 layers of $1.5 \mathrm{~mm}$-thick Perspex frames, sandwiched with 6 sheets of wire cloth alternately. 2 solid sheets of the same Perspex used as the top and bottom cover of the chamber. 2 holes were drilled at both the width side as the inlet and outlet point while 2 small holes were bored at the top of the chamber for bubbles control. Flowable silicone glue was applied to the entire outer surface as finishing. 2 chambers with internal width size of $1.2 \mathrm{~cm}$ and $2.5 \mathrm{~cm}$ is constructed.

\subsection{DEP separation experiment.}

The chamber as in Figure 2 experimental setup was firstly filled up with distilled water. A frequency generator (model TG120, ThurlbyThandar Instrument, UK) and a self-built amplifier (Basecore (M) SdnBhd, Malaysia) were used to supply voltages of up to $60 \mathrm{Vpk}-\mathrm{pk}$. By using a syringe, $1 \mathrm{ml}$ of cell suspension was immediately introduced after the electric field was applied to the system. Then, distilled water was continuously fed through the chamber inlet using a peristaltic pump (Watson-Marlow, UK) to wash out the cells that did not attract to the wire cloth. Few minutes later, the flow was stopped, the applied voltage was taken off, and the chamber was back flushed to collect the suspension for analysis. Experiments were conducted to observe the effects of applied voltage, flow rate and cell concentration towards the DEP separation process.

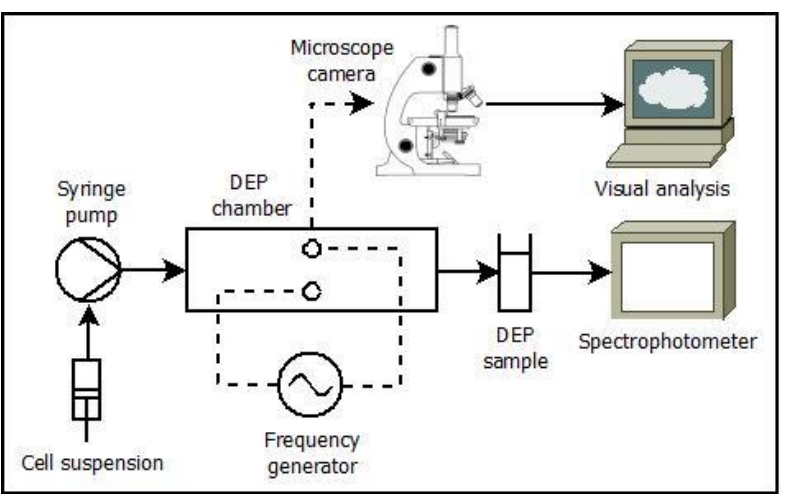

Figure 2. The schematic diagram of the DEP experiment setup

Variation of applied voltage A set of experiments was carried out at different voltage from $0 \mathrm{Vpk}$-pk to $60 \mathrm{Vpk}$-pk. The frequency and flow rate conditions were $1 \mathrm{MHz}$ and 1 $\mathrm{ml} \mathrm{min}{ }^{-1}$ respectively. The OD of the inlet cell suspension was 0.92 .
Variation of flow rateFlow rates varies from $1 \mathrm{ml} \mathrm{min}^{-1}$ to $5 \mathrm{ml} \mathrm{min}{ }^{-1}$ was used with frequency fixed at $1 \mathrm{MHz}$ while the applied voltage value used was $30 \mathrm{Vpk}-\mathrm{pk}$.

Variation of cell concentration Cells suspensions with initial optical density absorbance (A) of 0.2, 0.4, 0.8, 0.9, 1.5, 2.0 were prepared. The frequency, applied voltage and flow rate used were $1 \mathrm{MHz}, 30 \mathrm{Vpk}$-pk and $3.5 \mathrm{ml} \mathrm{min}^{-1}$ respectively.

\subsection{Analytical Methods}

The experimental data were analysed and expressed in terms ofpercentage $\%$ mechanical yield, percentage $\%$ sedimentation loss, percentage $\%$ total yield or percentage $\%$ electrical yield. The percentage $\%$ of mechanical yield and sedimentation loss are essentially the same which denotes the percentage of cells trapped inside the system at $0 \mathrm{~V}$. The percentage $\%$ total yield is the total percentage of cells trapped inside the chamber after the application of the electric field. Finally, the percentage $\%$ electric yield is the percentage cells collected due only to the application of the electric field. As an approximation, it was assumed that the total yield minus the mechanical loss gave the electrical yield. The basic formulas are summarized as follows:

\section{At 0 V,}

percentage \% mechanical yield or sedimentation loss $=\frac{\text { no of cell in }- \text { no of cells out }}{\text { no of cells in }} \times 100$

\section{After the application of electric field,}

percentage $\%$ electrical yield

$=\frac{\text { no of cell in }- \text { no of cells out }- \text { no of cells trapped by mechanical }}{\text { no of cells in }} \times 100$

\section{RESULTS AND DISCUSSIONS}

\subsection{Electric Field Simulation of Wire Cloth Electrode}

In the first part of the work, electric field pattern and strength was simulated first to calculate the dielectrophoretic force and also its non-uniformity behaviour. Through simulation by COMSOL, a maximum value of electric field obtained was $1.340 \times 10^{6} \mathrm{Vm}^{-1}$ as can be seen in Figure 3 and Figure 4. The electric field strength is recorded to be the highest at the edge of electrode. As one move away from the edges, the electric field strength decreases non-linearly. This result is supported by previous works done by other researchers [13]. Electric Field pattern shown in Figure 3 and 4 clearly indicate non-uniformities which is an important essential features for a successful DEP separation system. The maximum electric field strength and DEP force obtained here yield approximately $3.1 \times 10^{15} \mathrm{~V}^{2} \mathrm{~m}^{-3}$ and 3.7 $\times 10^{-10} \mathrm{~N}$ which conformed to previous investigation [16, 17]. This value is sufficient to produce a significant attractive force for DEP separation to occur. By Navier Stokes equation, the drag force was calculated approximately $2.6 \times 10^{-10} \mathrm{~N}$ when doing a force balance on a single particle, gave a particle velocity of $4 \times 10^{-5} \mathrm{~m} / \mathrm{s}$ moving forwards towards the end of the separation chamber. 


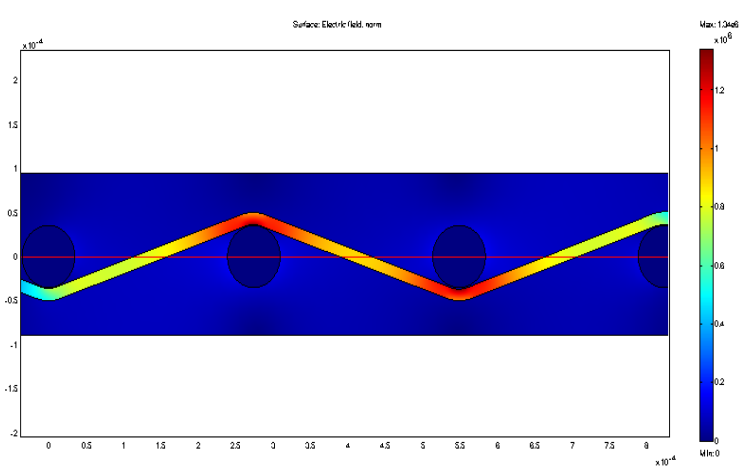

Figure 3: The simulation of $71 \mu \mathrm{m}$ wire cloth system with gap of $204 \mu \mathrm{m}$ and yarn $16 \mu \mathrm{m}$. Maximum value of electric field obtained was $1.340 \times 10^{6} \mathrm{~V}^{2} \mathrm{~m}^{-3}$

\subsection{Optimization of Microorganism Separation}

This part discussed on the effect of the parameters studied which were the applied voltage, flow rate, cell concentration and the chamber width.

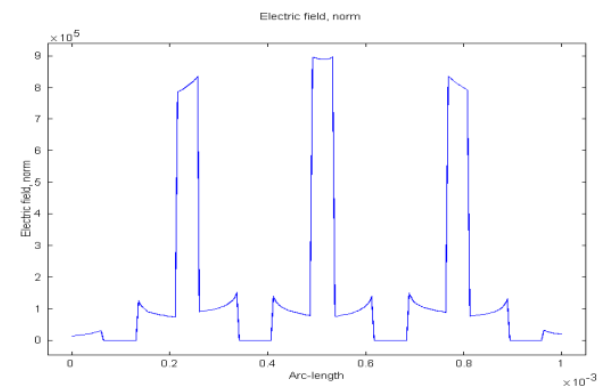

Figure 4: The electric field plot across the red line as in Figure 3. This plot shows the variation of the electric field along the $x$-axis for the wire cloth system. It was recorded that the average electric field was $9 \times 10^{5} \mathrm{~V}^{2} \mathrm{~m}^{-3}$

\subsubsection{Variation of applied voltage}

As depicted in Figure 5, the optimum voltage of 30Vpkpk was obtained with cell collection yield of 96.13\%. and the increment of the applied voltage only resulted to the decrease on the yield due to the interference by DC currents produced by the amplifier when high voltage and currents are used. Factors of electrode overheating also contribute to cell being non-viable towards the dielectrophoretic force available. The results found in this work is slightly higher and comparable to previous work $[13,15,16]$.

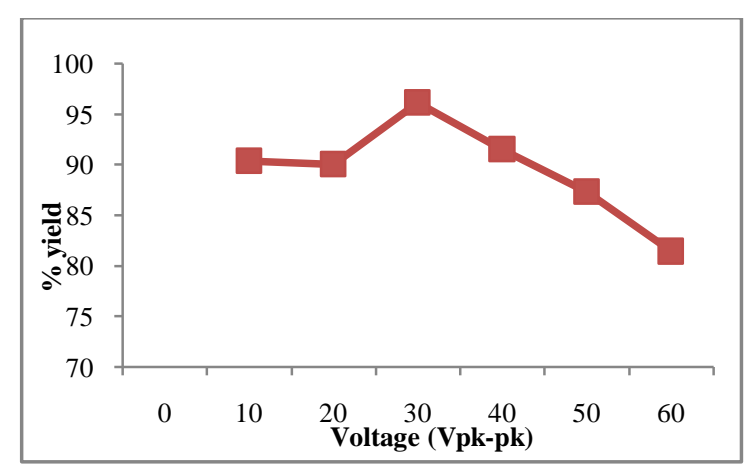

Figure 5 The percentage of cells collection by wire cloth in the DEP chamber as a function of voltage. Fixed parameters of $1 \mathrm{MHz}$ frequency with flow of $1 \mathrm{ml} / \mathrm{min}$ and cell concentration at $\mathrm{OD}$ of $0.92 \mathrm{~A}$ was used.

\subsubsection{Variation of flow rates}

Flow rate is the parameter that influence the drag force needed for the dielectrophoretic separation system. The flow rates were varied from 1 to $5 \mathrm{ml} / \mathrm{min}$ with fixed parameters of $1 \mathrm{MHz}$ of frequency, $30 \mathrm{Vpk}-\mathrm{pk}$ of applied voltage and cell concentration of $0.92 \mathrm{~A}$. The optimum flow rate was obtained at $3.5 \mathrm{ml} / \mathrm{min}$ (Figure 6). Higher flow rates distract the cells from the DEP force while lower flow rate caused Brownian motion between the bacteria cells to disturb the formation of the pearl chain [4].

Sedimentation tends to happen in large scale flow system because of gravity inside the chamber in regards to the mass of the particular microorganism [13]. However, the sedimentation percentage obtained was small compared to the total yield, hence the total yield in the end equals to the electrical yield. The usage of E. coli bacteria that is much smaller than yeast defies gravitational force issue entailed during the use of yeast. Yet some loss of cells was recorded at the final analysis during the reducing of the final sample by centrifuging. The results in this work is similar as in previous reported literature $[13,17]$.

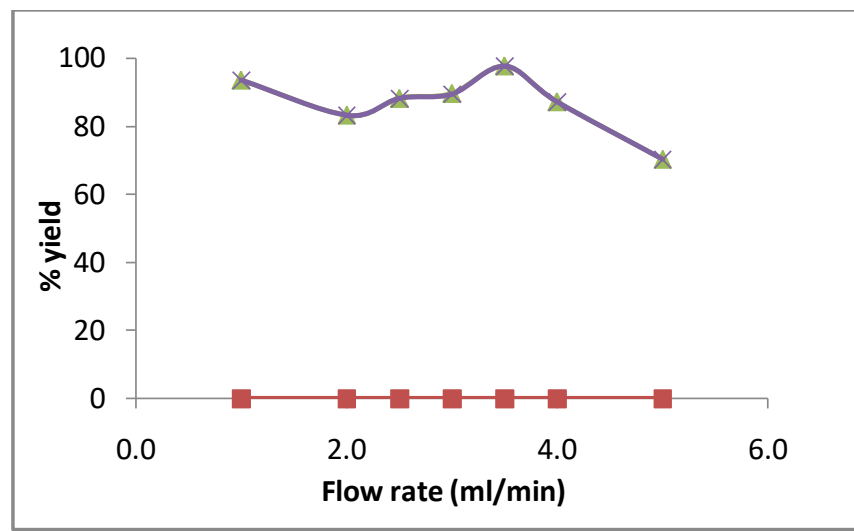

Figure 6 The effect of flow rate to the percentage yield of cell collected at $30 \mathrm{Vpk}-\mathrm{pk}, 1 \mathrm{MHz}$ and $0.92 \mathrm{~A}$. The sedimentation yield is very low $(<0.01 \%)$ and the highest yield observed was $97.6 \%$ at $3.5 \mathrm{ml} / \mathrm{min}$.

\subsubsection{Variation of cell concentration}

Figure 7 shows a nearly-zero sedimentation rate and the gradual increase of electrical percentage collection with cell concentration until it reach plateau and no longer change or saturate which is similar to previous findings [13], The maximum $\%$ yield achieved was $89 \%$ at $2.08 \times 10^{7}$ cell $/ \mathrm{ml}$. Asa can be seen, the cell number increased but not the sedimentation rate confirmed the influence of gravitational force on E.coli was insignificant. 


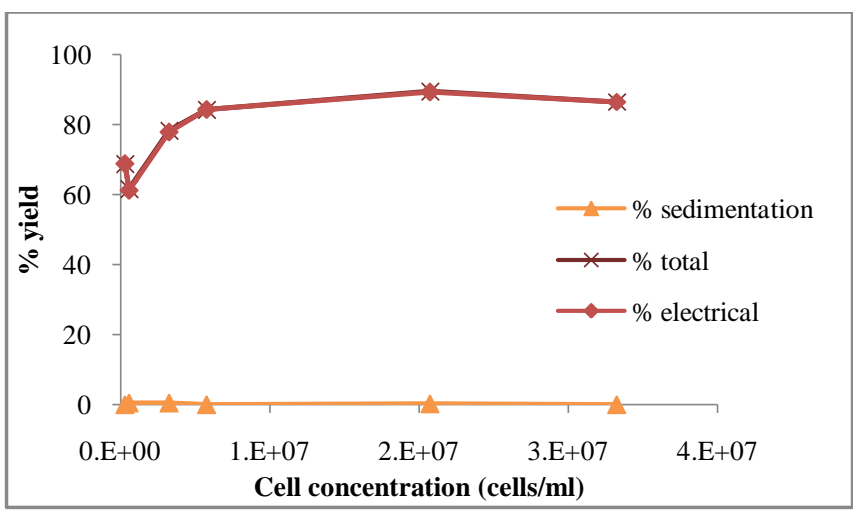

Figure 7 The variation of cell concentration observed at value as low as $2.89 \times 10^{5}$ cells $/ \mathrm{ml}(\mathrm{OD}=0.2 \mathrm{~A})$ until $3.33 \times 10^{7}$ cells $/ \mathrm{ml}(O D=2.0 \mathrm{~A})$. The voltage used was 30 Vk-pk at $1 \mathrm{MHz}$ frequency and flow rate of $3.5 \mathrm{ml} / \mathrm{min}$.

\subsubsection{Width chamber comparison}

The width of the chamber and its effect on the \% yield was investigated with chamber A (width $1.2 \mathrm{~cm} \times 1.7 \mathrm{~cm}$ ) and chamber B (width $2.5 \mathrm{~cm} \times 1.7 \mathrm{~cm}$ ). The 2 chambers were built with different cross sectional area and length to travel.

Chamber A which have smaller width but longer in length in turn have a slightly higher percentage of yield instead of chamber B (Figure 8) which was built with larger width but shorter in length. This is due to longer distance travelled by the cells that helps the DEP separation of cells due to longer retention time compared to wide but shorter distance at chamber B. This concept is similar to chromatography principles. Longer length facilitates better separation of different types of microorganisms or analytes and hence results in a greater resolution of the different samples obtain. Furthermore, the particles in chamber B with bigger cross sectional area may experience greater Brownian diffusion motions compared to smaller cross sectional area.

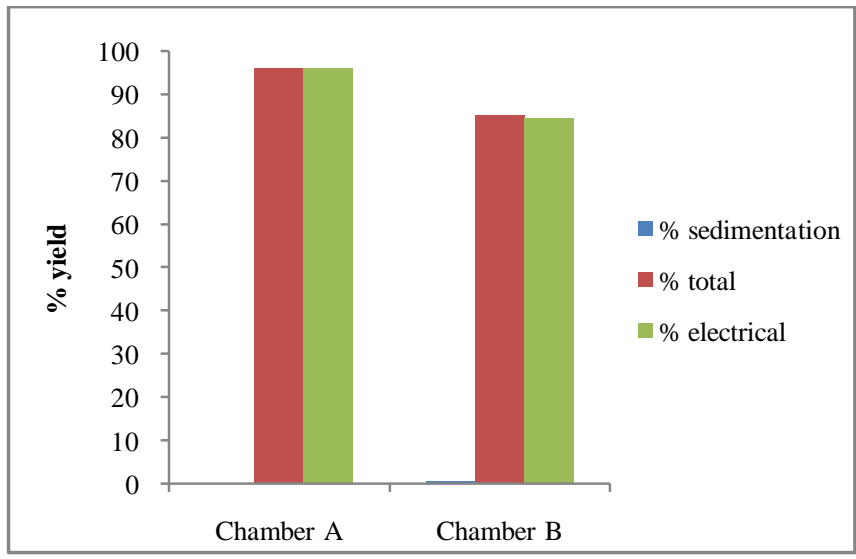

Figure 8 The yield obtained by different width chambers, with total \& electrical yield of $96 \% \& 96 \%$ for Chamber $A$ and $85 \%$ \& $84 \%$ for Chamber B. \% sedimentation yield were nearly zero for both chambers.

Fixed parameters of flow rate $(3.5 \mathrm{ml} / \mathrm{min})$, applied voltage $(30 \mathrm{Vpk}-\mathrm{pk})$ and cell concentrations $(\mathrm{OD}=0.92 \mathrm{~A})$ were used.

\section{CONCLUSIONS}

The DEP separation of bacteria cell was made possible in higher throughput with the use of wire cloth electrode system. There are much more factors surrounding the principles of DEP but particularly for this study, the optimum variables of $30 \mathrm{Vpk}-\mathrm{pk}$, flow rate of $3.5 \mathrm{ml} / \mathrm{min}$ and cell concentration of $2.08 \times 10^{7}$ cells $/ \mathrm{ml}$ was recorded with the better performance on the less wide chamber.

\section{ACKNOWLEDGEMENTS}

The project and student has been funded by MOSTI through EScience Fund (01-03-04-SF0841).

\section{REFERENCES}

1. Doble M, Kruthiventi A and Gaikar V 2018 Biotransformations and Bioprocesses / M. Doble, A.K. Kruthiventi, V.G. Gaikar.

2. Pohl H A and Crane J S 1971 Dielectrophoresis of Cells Biophys J11 711-27

3. Yildizhan Y, Erdem N, Islam M, Martinez-Duarte R and Elitas M 2017 Dielectrophoretic Separation of Live and Dead Monocytes Using 3D Carbon-Electrodes Sensors (Basel)17 2691

4. Markx G H, Talary M S and Pethig R 1994 Separation of viable and non-viable yeast using dielectrophoresis $J$ Biotechnol32 29-37

5. Pethig M S T and J P H B and J A T and R 1996 Electromanipulation and separation of cells using travelling electric fields J Phys D Appl Phys29 2198

6. Cheng I F, Froude V E, Zhu Y, Chang H C and Chang H C 2009 A continuous high-throughput bioparticle sorter based on 3D traveling-wave dielectrophoresis Lab Chip

7. Nakidde D, Zellner P, Alemi M M, Shake T, Hosseini Y, Riquelme M V, Pruden A and Agah M 2015 Three dimensional passivated-electrode insulator-based dielectrophoresis Biomicrofluidics 914125

8. Abidin Z, Fakhru'l-Razi A, York Chow W and Hafifudin N 2013 Construction of ASMC by Dielectrophoresis Using Wirecloth Electrode for the Treatment of Wastewater Dev Sustain Chem Bioprocess Technol 65

9. P. H M 2002 Strategies for dielectrophoretic separation in laboratory-on-a-chip systems Electrophoresis 23 2569-82

10. Hughes M P, Morgan H and Rixon F J 2001 Dielectrophoretic manipulation and characterization of herpes simplex virus-1 capsids Eur Biophys J30 268-72

11. Fatoyinbo H O, Kamchis D, Whattingham R, Ogin S L and Hughes M P 2005 A high-throughput 3-D composite dielectrophoretic separator. IEEE Trans Biomed Eng52 13479

12. Faraghat S A, Hoettges K F, Steinbach M K, van der Veen D R, Brackenbury W J, Henslee E A, Labeed F H and Hughes M P 2017 High-throughput, low-loss, low-cost, and label-free cell separation using electrophysiology-activated cell enrichment Proc Natl Acad Sci114 4591 LP-4596

13. Abidin Z Z, Downes L and Markx G H 2007 Novel electrode structures for large scale dielectrophoretic separations based on textile technology J Biotechnol130 183-7

14. Ciprian I, Guolin X, Celeste L F, Lam O P and H. T F E 2007 A 3-D dielectrophoretic filter chip Electrophoresis28 1107-14

15. Li S, Li M, Bougot-Robin $\mathrm{K}$, Cao W, Yeung Yeung

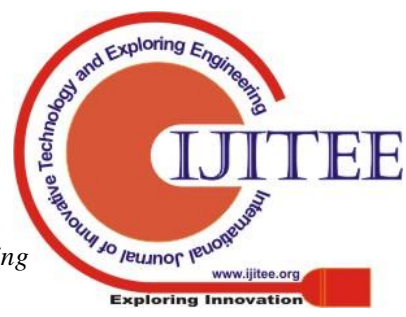


Chau I, Li W and Wen W 2013 High-throughput particle manipulation by hydrodynamic, electrokinetic, and dielectrophoretic effects in an integrated microfluidic chip Biomicrofluidics 724106

16. Abidin Z Z, Abdullah a G L, Yunus Z, Markx G H and Science A 2007 Wire Cloth Electrodes : A Study of Electric Field for Dielectrophoretic Separation of Cells vol 4

17. Fadhila Nadzri, Zurina Zainal Abidin, Jamil Salleh. IOP Conference Series: Materials Science and Engineering, Effects of Wire diamater, yarns size and wire configuration to wire cloth electrode produced from textile technology for dielectrophoresis application. Volume 458. 